\title{
BREVE INTRODUÇÃo AO PENSAMENTO TRADUTOLÓGICO DE JIŘí LEVÝ ${ }^{1}$
}

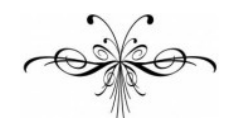

FiLIPE MENDES NeCKEL

Resumo: Neste artigo, apresento os aspectos mais salientes da teoria da tradução do historiador e pesquisador tcheco Jiř́i Levý (1926-1967). Por meio de uma re-construção introdutória, lanço luz sobre dois trabalhos de meados dos anos 60 representativos de seu pensamento, que, contudo recebeu pouco ou nenhum reconhecimento por seus pares no Ocidente; a saber: Die literarische Übersetzung (1969 [1963]) e Translation as a decision process (2000 [1966]) - traduzidos ao português, nessa ordem, integral e parcialmente, neste número de Scientia Traductionis. Oferece-se, pois, um panorama do papel de Levý como teórico e destacase a importância de suas teorias para a história, a crítica e a prática da tradução.

Palavras-chave: Jiří Levý; Estudos da Tradução; tradução literária

\begin{abstract}
In this article I present the most prominent features of the translation theory of Jiří Levý - a Czech historian and researcher. By means of an introductory reconstruction, I shed light upon two of his works dated from the 60s which are representative of his thought, which, however, received little to no recognition by his peers in the West: Die literarische Übersetzung (1969 [1963]) and Translation as a decision process (2000 [1966]), translated into Portuguese fully and partially, respectively, in this issue of Scientia Traductionis. A panorama of Levý's role as a theoretician is offered and the importance of his theories to the history, critique and practice of translation is highlighted.
\end{abstract}

Keywords: Jiří Levý; Translation Studies; literary translation

\footnotetext{
${ }^{1}$ Artigo baseado em minha dissertação de mestrado, intitulada Die literarische Übersetzung: apresentação da obra de Jiř́ Levý acompanhada de uma tradução comentada, defendida em julho de 2011 (PGET-UFSC).
} 
$\mathrm{E}$ mbora em seu tempo o pensamento de Levý sobre tradução tenha sido relegado ao esquecimento - por razões políticas, culturais e linguísticas, conforme nos informa Cernuda $(2011)^{2}-$, estudos contemporâneos o colocam em uma posição de destaque, não só do ponto de vista cronológico - por ter desenvolvido uma teoria de tradução robusta já nos anos 60 - como também qualitativo - visto que sua teoria afina-se com ideias tradutológicas tradicionais, como, por exemplo, sua dicotomia das traduções ilusionista / anti-ilusionista, afins aos dois métodos tradutórios de Schleiermacher $^{3}$-; também, porque, com vanguardismo, pode ser considerado um prédescritivista, uma vez que elementos de sua teoria precedem parte do que defende a Teoria dos Polissistemas (Jettmarová, 2011, p.51).

Em sua obra, pretendeu isolar os fatores que afetam o trabalho do tradutor durante o processo tradutório e, com isso, tentou apresentar o modo como uma maneira particular de traduzir modifica potencialmente o efeito que um texto tem sobre seu leitor final. Sua preocupação com o tradutor e com suas escolhas também o credita como um teórico de vanguarda, pois respeita não apenas a individualidade do tradutor mas também sua criatividade, situando esse último em uma posição de igualdade com o autor quanto à originalidade da criação, visto que os dois interferem no sistema literário em que estão inseridos.

Um dos pontos mais relevantes da teoria de Levý esta ancorado nas escolhas que o tradutor faz durante seu processo criativo. Os caminhos que o tradutor percorre para construir seu texto passam por interpretações alternativas de palavras, de elementos textuais, de partes do texto e mesmo do texto como um todo ${ }^{4}$, isto é, é a partir das escolhas que faz que produz seu texto.

Para que se possa entender melhor como Levý constrói seu conceito de "escolha", apresento a seguir as principais ideias que desenvolve no artigo Translation as a Decision Process, escrito em 1966 e republicado em 2000, na obra The Translations Studies Reader, organizada por Lawrence Venuti ${ }^{5}$, e neste 2012, na presente edição de Scientia Traductionis, junto de sua tradução ao português ${ }^{6}$. Levý, nesse artigo, vê a tradução sob dois pontos de vista: um teleológico - isto é, em que a finalidade da tradução é a de servir como um processo de comunicação cujo objetivo é partilhar o conhecimento do original com o leitor estrangeiro - e outro pragmático - em que, ao partir do tradutor no exercício de sua tarefa, indica que a tradução é um processo de tomada de decisões. Segundo o teórico tcheco, em sua prática, uma série de possibilidades se apresenta ao tradutor, submetendo-o à necessidade de tomar decisões dentre um número determinado de alternativas que lhe surgem durante o processo tradutório.

\footnotetext{
${ }^{2}$ Conferir o artigo de Miguel Ángel Vega Cernuda, El caso Levý: Fenomenología de su recepción y valoración de sus aportaciones en el contexto de la Traductología de la época, publicado bilingualmente neste número de Scientia Traductionis, pp. 153 a 171.

${ }^{3}$ Ver: SCHLEIERMACHER, Friedrich. Dos diferentes Métodos de Tradução. [Trad. Mauri Furlan]. In Scientia Traductionis (UFSC). Florianópolis, n. 9, 2011, p. 23.

${ }^{4}$ BROECK, Raymond van den. "Translational Interpretation: a complex strategic game". In Translators' Strategies and Creativity: Selected Papers from the 9th International Conference on Translation and Interpreting, Prague, September 1995: In Honor of Jiri Levy and Anton Popovic. Prague: International Conference on Translation and Interpreting, 1995. KRALOVA, J.; Mercer, B. M.; Ozeroff, A. B. Amsterdam: John Benjamins B.V., 1998, p.5.

${ }^{5}$ VENUTI, Lawrence (org.). Translation Studies Reader. London: Routledge, 2000, p.148.

${ }^{6}$ N.E.: Conferir pp. $72-96$.
} 
As tomadas de decisão realizadas pelo tradutor podem variar dependendo do contexto em que a obra traduzida está inserida ou o que essa pretende representar; ou seja, as 'instruções' para a escolha - a classe de possíveis alternativas de tradução (Levý, 2000, p.149) - dentre as possibilidades elencadas pelo 'paradigma' - a classe de possíveis soluções de tradução para uma palavra ${ }^{7}$ (idem, p. 150) ${ }^{8}$ - são dadas, mais das vezes, pelo contexto; o tradutor precisa então escolher entre uma quantidade de possíveis sentidos da palavra e lidar com algumas outras restrições, como estilo ou ponto de vista do autor, além da condição histórico-filológica do texto.

Segundo Levý, dois tipos de instruções permeiam as escolhas do tradutor: a "instrução definicional", que circunscreve e classifica um determinado paradigma, apresentando soluções para a tradução relacionadas ao seu valor contextual, e a "instrução seletiva", que diz respeito à escolha do tradutor dentre as possibilidades elencadas pela instrução definicional - por exemplo, a escolha entre "rapaz" ou "cara", conforme indicar o contexto.

As escolhas de que nos fala Levý não se restringem unicamente a uma palavra ou segmento textual, mas também dizem respeito à maneira como será realizada a tradução, qual função ${ }^{9}$ o tradutor atribuirá ao seu texto na língua e cultura de chegada. Essa escolha cabe ao tradutor. Ele pode trazer novos usos para sua língua e arriscar-se, ou manter o status quo e preservar-se, produzindo uma tradução que apenas reproduz o já estabelecido pela tradição tradutória. A esse respeito, já dissera em sua obra de 1963:

Uma tradução das formas atípicas para nós, e ainda assim altamente convencionais da poesia oriental (por exemplo, os Hassidim persas) despertará, no primeiro contato com o leitor europeu, a impressão de uma nova forma original. O leitor não compreenderá, portanto, na primeira coletânea de poesias, seu valor cultural objetivo. No entanto, quando tiver lido o quinto ou décimo volume escrito nessa forma, já o tomará por convencional. A possibilidade de uma tradução não depende unicamente da maturidade do método tradutório, mas também da maturidade do leitor. Uma tradução perfeita exigiria não apenas um tradutor ideal, mas também um leitor ideal. $\mathrm{O}$ tradutor pode efetuar uma ampliação do conhecimento da cultura estrangeira no leitor e, desse modo, conseguir aplainar o caminho para outros intérpretes dessa cultura, fazendo com que esses possam contar com um leitor melhor informado. (Levý, 1969, p. 75$)^{10}$.

As escolhas do tradutor são a materialização da percepção que teve do texto de partida, e essa percepção é que chegará ao leitor de seu texto de chegada; de fato, é sua interpretação do texto traduzido.

\footnotetext{
${ }^{7}$ Não se restringe a uma listagem de sinônimos, mas compreende um conjunto ordenado por diferentes critérios, tais como, nível estilístico, sentido, contexto, etc.

${ }^{8}$ N.E.: Sobre esses conceitos usados por Levý, termos técnicos seus, - 'instrução'/‘instruções' e 'paradigma' -, conferir pp.73 e 74 neste número de Scientia Traductionis.

${ }^{9}$ A teoria de tradução tcheca remonta à virada do século XIX para o XX, tem sua origem no estruturalismo funcional tcheco e é conhecida como uma teoria funcional da tradução. Portanto, o termo "função" em Levý alinha-se ao conceito do estruturalismo tcheco, em que representa um vetor entre o objeto e seu sujeito agentivo (usuário) (JETTMAROVÁ, 2011, p.54; conferir pp. 134 e 139 deste número de Scientia Traductionis).

10 N.E.: São de Filipe Neckel todas as traduções de citações da obra Die literarische Übersetzung (1969), exceto as extraídas do excerto bilíngue publicado nesta edição de Scientia Traductionis, tradução conjunta de Filipe Neckel e de Marcelo Rondinelli (conferir pp. 24-60).
} 
Além disso, os valores semânticos e estilísticos de palavras e expressões interferem nas tomadas de decisão do tradutor, podendo estabelecer o rumo que uma tradução irá seguir. Desse modo, é preciso que o tradutor reconheça, no texto de partida, a força que determinado termo exerce, de maneira que opte por um termo na língua de chegada que transmita ao leitor da tradução a função ${ }^{11}$ que foi transmitida ao leitor primeiro, tendo em mente que, ao optar por um caminho, estabelece para a tradução um campo de jogo, e uma determinada gama de possibilidades se descortina para a sua atuação a partir disso. Essa teoria de Levý expõe, portanto, sob bases estruturais, que uma escolha anula outra possível alternativa, e que a primeira escolha predetermina as escolhas posteriores, criando, assim, um contexto para as decisões subsequentes.

O processo de tomada de decisão do tradutor revela a forma como compreende, e posteriormente escolhe para representar em seu texto, as propriedades inerentes ao texto de partida; por exemplo, a maneira como uma situação completamente alheia à sua cultura tradutor será introduzida na tradução; ou como a concepção de determinado personagem, que dentro de seu contexto é significativa para a compreensão da obra, alcançará a cultura e o leitor de chegada; ou, ainda, o que será passado ao leitor da tradução do estilo ou mesmo da ideologia do autor. Assim, ao tomarem decisões diferentes, dois tradutores realizarão traduções distintas uma da outra, pois haverão escolhido jogos diversos. Porém, quanto mais restrito o contexto e menor o número de possibilidades apresentadas pelo texto de partida, sejam essas semânticas, rítmicas, lexicais, etc, mais próximas serão as duas traduções.

As relações, ou possibilidades de escolhas, que se estabelecem entre o texto de partida e o de chegada são devidas àquilo que Levý chama de 'tendências divergentes e convergentes'. Tendências divergentes apresentam um paradigma de escolha maior, ou seja, a língua de chegada possui uma riqueza de expressões que permite que cada tradutor faça uma escolha particular na tradução de um mesmo texto. Por outro lado, em casos de tendências convergentes, em que o paradigma é mais limitado, as traduções tornam-se mais semelhantes entre si.

Essa relação também se aplica a construções interpretativas mais complexas, como, por exemplo, as características que tornam uma obra relevante frente a outras, sua originalidade. E para que a tradução alcance tal magnitude na cultura alvo, se torne pura novidade, tal como a obra que lhe é base na cultura fonte, o tradutor deve tomar a tradução, ao mesmo tempo, como um processo interpretativo e criativo.

Essa abertura a múltiplas escolhas na tradução confere ao tradutor certa liberdade autoral. De acordo com o teórico tcheco, o processo de tomada de decisão permite ao crítico e ao analista de traduções ter uma visão de todo o percurso tradutório. Desse modo, baseando sua observação nas escolhas finais, no trabalho terminado, seria possível determinar quais foram os passos que o tradutor seguiu ao realizar sua tarefa, e, a partir desse ponto de vista, aproximar a prática tradutória da teoria propriamente dita.

Em sua reflexão, ao analisar textos traduzidos e de partida, Levý não busca estabelecer uma tradução única e ideal, estando concentrado em observar as soluções tradutórias que podem variar dependendo do tradutor e do momento

\footnotetext{
${ }^{11}$ Vide nota 8.
} 
histórico e cultural no qual está inserido. Desse ponto de vista é que é possível considerá-lo como um precursor do 'Descritivismo' nos Estudo da Tradução.

O vanguardismo de Levý também é evidente em sua obra de maior fôlego, Uměni Překladu, de 1963. Está dividida em duas partes, a primeira voltada à teoria da tradução literária e a segunda exclusivamente à tradução de poesia. $\mathrm{O}$ comentário que segue foi baseado na tradução dessa obra ao alemão, sob o título Die literarische Übersetzung (1969) ${ }^{12}$.

Esse trabalho estabeleceria uma nova dimensão para os estudos sobre a tradução, visto que há nele uma tentativa de confluência da teoria com a prática. Diz o tradutor alemão, em seu prefácio de 1969, que

este livro poderia criar uma ponte entre teoria e prática. Por um lado, quer dar suporte ao tradutor em seu trabalho prático, acentuar os problemas e apresentar possibilidades de solução. [...] Por outro, quer chamar a atenção do historiador literário para a tradução enquanto gênero artístico, que ainda não foi sistematicamente estudado com métodos modernos. (Levý, 1969, p. 10)

Em seu primeiro capítulo, Levý nos dá um panorama do que se disse até então sobre a tradução, tratando dos mais modernos pensamentos disseminados àquela época sobre o traduzir e suas questões. Posiciona-se de maneira desfavorável à situação em que se encontrava a teoria da tradução, visto que se baseava em "reflexões empíricas e aforismos ensaísticos" (Levý, 1969, p. 13).Em contrapartida, propôs observações que pudessem contribuir para a formulação de uma teoria da tradução que fosse especializada. Segundo o autor,

um ponto de partida mais efetivo para a elaboração de teorias de tradução detalhadas e especializadas é a precedência pela conservação de aspectos particulares do texto traduzido - e isto depende da estrutura do texto escrito ou falado e não do objetivo, do qual a tradução deve se servir. (1969, p. 18).

De acordo com sua teoria, por se tratar de um processo comunicativo, a informação contida na tradução pode ser dividida em duas categorias: elementos invariáveis - que, por sua natureza, devem permanecer inalterados no final do processo tradutório - e elementos variáveis - que representam as estruturas que serão alteradas na tradução por outras estruturas com valores e funções semelhantes na língua e cultura alvo. Levý entende que essas categorias podem ser aplicadas a diversos tipos de tradução A relação entre objetos variáveis e invariáveis em um texto é que determina sua dificuldade tradutória; quanto mais elementos invariáveis, mais dificuldades se apresentarão no processo tradutório.

Dois métodos de estudo da tradução vigentes àquela época foram observados e adotados por Levý, a saber: o linguístico e o literário. De um ponto de vista linguístico, como característica principal de sua teoria, Levý propõe um modelo estruturalista-funcional da tradução voltado à investigação de qual função comunicativa os elementos linguísticos particulares possuem e quais meios linguísticos podem preencher a mesma função dentro de uma mesma língua. Já o método literário baseia-se no fato de a tradução, assim como a literatura origi-

\footnotetext{
${ }^{12}$ Levý auxiliou o tradutor alemão Walter Schamschula não apenas elucidando dúvidas, mas teve uma participação ativa no processo tradutório, co-criando uma terminologia específica e construindo os exemplos ofertados de forma clara para o leitor alemão; contudo, morreu antes de ver a tradução publicada em sua versão final.
} 
nal, possuir uma "personalidade"; por conseguinte, aspectos que revelam a poética do tradutor podem ser investigados da mesma forma que a do autor. Nesse sentido a análise do momento histórico do qual o tradutor faz parte, de sua poética, como diferenciadora dos estilos e desenvolvimentos literários de dois povos, pode ser realizada.

A partir de sua concepção de tradução - em que relaciona as características literárias da tradução ao texto fonte, unidas às escolhas culturais que envolvem o fazer tradutório -, Levý concebe dois métodos de tradução: o ilusionismo e o anti-ilusionismo. No primeiro método "o tradutor ilusionista oculta-se atrás do original, o qual apresenta ao leitor sem intermediários, por assim dizer, com o objetivo de despertar neste a ilusão tradutória, ou seja, a ilusão de que lê o original" (Levý, 1969, p. 31). Em contrapartida, no segundo método, o tradutor, não só caracteriza seu texto como tradução, mas simula a realidade, interfere no andamento da narrativa, acrescenta seu ponto de vista, se dirige diretamente ao leitor, entre outros. O método que Levý segue para elaborar sua teoria é o 'ilusionista'. Embora sua intenção não seja a de que a experiência do leitor do original deva ser idêntica a do leitor da tradução, procura trabalhar com uma noção de identidade a partir de uma perspectiva funcional ${ }^{13}$. Destarte e a esse respeito, o que se deve levar em conta, segundo Snell-Hornby (2006, p.22), é "o princípio holístico, a subordinação das partes e dos detalhes ao texto como um todo, visto de acordo com sua função dentro do sistema (literário) e dentro de um contexto histórico e cultural."14

Conforme Levý, as questões referentes ao processo que origina a tradução podem ser abordadas a partir da relação entre três componentes: 1) o conteúdo da obra ${ }^{15}$; 2) a concretização da obra pelo leitor do texto fonte, e 3) sua segunda concretização, pelo leitor da tradução. Assim, o processo tradutório não se conclui com o término da escrita, do mesmo modo que o texto fonte não está concluído quando o autor o "passa ao papel"; somente quando é lido é que produz algum efeito na sociedade, e, assim como o texto fonte, a tradução pode ser aceita ou não. Ao comentar sobre esse assunto em Levý, diz Snell-Hornby:

O processo de recepção "normalmente" termina com a reconstrução da obra literária na mente do leitor. Mas o tradutor difere do "leitor normal" visto que deve formar uma ideia da obra e colocá-la em palavras para um outro leitor, e da mesma maneira que o original a tradução somente tem relevância social quando é, dito propriamente, lida. [...] E isso quer dizer, como viria a ser ressaltado pela abordagem funcionalista nos anos 80 , que o tradutor tem de trabalhar com os leitores em mente, e antecipar como seu texto poderá ser visualizado por eles. (Snell-Hornby, 2006, p.23).

Após caracterizar o processo que dá origem à tradução, Levý propõe uma descrição do que seria o trabalho tradutório, e o divide em três pontos:

1. Apreensão do original

2. Interpretação do original

\footnotetext{
${ }^{13}$ Conforme o conceito de 'função' comentado na nota 8.

${ }^{14}$ Todas as citações foram traduzidas por mim, com exceção daquelas traduzidas em conjunto com Marcelo Rondinelli.

${ }^{15}$ Segundo Levý (1969, p.37), o conteúdo que deve ser preservado na tradução é aquele ideado esteticamente, não sendo necessário, portanto, manter a forma linguística.
} 


\section{Transposição do original}

No que concerne à apreensão do original, o tradutor percorre três fases distintas, mas que podem ocorrer concomitantemente. Primeiramente, há a apreensão filológica do texto, quando a leitura se dá em um nível superficial de entendimento. Em seguida, passa-se à busca por seu valor estético, isto é, por palavras e expressões que fogem do entendimento comum e que estão ligadas a um nível mais profundo de leitura. Nesse caso, ao "perder" uma dessas palavras ou expressões conotativas, o tradutor deixa de passar ao leitor uma função estética contida no texto. Na última fase da apreensão, são abordadas as relações mais amplas; por exemplo, ligações entre os personagens, características que formam a realidade do texto, sua verossimilhança, assim como as ideologias expressas pelo autor, explícita ou veladamente. Essa apreensão da realidade do texto fonte é fundamental para que o tradutor não apenas consiga reproduzir essa realidade, mas também para que possa apresentá-la ao seu leitor sem antecipar eventos, ou revelar características que estariam ocultas para o leitor do texto fonte, por exemplo.

A interpretação do original provém da concepção que o tradutor tem da obra. Essa concepção, segundo Levý, seria semelhante àquela do historiador literário, e seu espaço de jogo estaria limitado pelos valores ideais e estéticos contidos no texto fonte. Os limites interpretativos estão condicionados ao conteúdo da obra e a seus elementos estéticos, sejam eles explícitos ou latentes. Apesar de existir a possibilidade de inúmeras interpretações para uma obra de arte, a introdução de uma determinada interpretação pelo tradutor - seja uma explicação inexistente, seja a alteração do efeito estético - destruiria a estrutura artística do original, acabando também com a essência da tradução. Afinal, o tradutor deve visar destacar mais a poética da obra do que a sua própria, sem impor-lhe suas ideias subjetivas.

A transposição do original em tradução se dá por meio de três fatores. Primeiramente, é preciso estabelecer a relação entre os dois sistemas linguísticos. Visto que os dois sistemas não são equivalentes, é preciso que o tradutor consiga resolver as questões relativas ao estilo e às forças semânticas que atuam em ambos os meios textuais, e para isso suas escolhas são fundamentais para que se restabeleçam os níveis funcionais do texto fonte no texto alvo. Em segundo lugar, porque as características do original afetam a tomada de decisão do tradutor, "há uma influência direta e uma indireta da expressão linguística do original sobre a tradução, o que possui efeitos positivos e negativos" (1969, p. $59)^{16}$, ou seja, tanto a novidade presente no texto fonte que o tradutor consegue trazer para sua língua quanto as particularidades da língua de partida que fazem com que seja desviado das normas padrão de sua língua se dão sob a influência do texto fonte. Por fim, ainda existe a tensão de se transpor um texto de uma língua para outra, reproduzindo um pensamento que não foi originalmente pensado para aquela cultura. Essa tensão pode resultar em um texto gramática e semanticamente perfeito, mas que mesmo assim parece artificial ao leitor. A prática tradutória exige do tradutor uma capacidade artística muito grande, para que seu texto não seja apenas a reprodução de um estilo estranho, incômodo ao lei-

\footnotetext{
${ }^{16}$ Essa tradução encontra-se na p.53 deste número de Scientia Traductionis.
} 
tor, mas que promova novas formas estilísticas em sua própria língua e cultura. Para Levý,

os requisitos que se colocam para o tradutor também determinam mais detalhadamente que tipo de talento a arte de traduzir demanda: acima de tudo, trata-se da imaginação, da capacidade de objetivar e do talento estilístico. (1969, p. 64$)^{17}$.

Demanda-se essa capacidade artística do tradutor sobretudo porque aqui a tradução é encarada como um gênero artístico. Diz: "a tradução como obra é uma reprodução artística, a tradução como processo, uma criação original, a tradução como gênero artístico, um caso limite na separação entre a arte reprodutiva e original" (1969, p.66).

Uma das principais dificuldades que Levý encontrou para a formulação de sua teoria são as tensões que se formam no processo tradutório, como por exemplo, a situação problemática da tradução de nomes próprios. Deve-se optar pela naturalização desses nomes ou mantê-los em suas formas estrangeiras? $\mathrm{Ou}$ uma hibridização solucionaria esse dilema? Essas questões não têm uma resposta única, sendo necessário que o tradutor escolha o que considera a melhor opção de acordo com o caso. Além disso, as dificuldades aumentam quando se trata da tradução de textos de períodos históricos distantes e/ou oriundos de culturas "exóticas". Sobretudo essa última dificuldade pode introduzir características positivas na sociedade alvo, ao apresentar, por exemplo, uma outra forma de narrativa, ou mesmo uma forma de pensamento, que, à primeira vista, poderia parecer absurda para a sociedade alvo, mas que, aos poucos, se agrega a sua forma de pensar. É tarefa do tradutor escolher o papel que sua tradução terá na literatura nacional; pode optar por manter as particularidades de sua literatura, ou pressupor no leitor um desejo pelo conhecimento da cultura estrangeira, e assim trazer, através de sua tradução, características distintivas da cultura fonte, revelando novas possibilidades de desenvolvimento para a literatura de seu país e/ou de sua comunidade linguística.

Entendida como gênero, uma tradução também pode alcançar o status de clássica, ou ideal, para uma geração. Isso foi, por exemplo, o que ocorreu por muitos anos com a tradução brasileira da obra Ulysses de James Joyce, traduzida por António Houaiss ${ }^{18}$. Não necessariamente é a melhor tradução que se torna um clássico; vários fatores contribuem para tal categorização, como a reação do público diante daquele texto, seu lugar dentro do espírito da época e da cultura da qual fez ou fará parte, entre outros. Disso decorre a efemeridade do status de clássica de uma tradução, que será aceita como tal, segundo Levý, apenas

enquanto ela for adequada aos fundamentos da língua e da interpretação deste período. Quanto mais rápido uma língua nacional se desenvolve, mais rápido envelhecem as traduções. $(1969,79)$

\footnotetext{
${ }^{17}$ Essa tradução encontra-se na p.60 deste número de Scientia Traductionis.

18 JOYCE, James. Ulysses [Trad. António Houaiss]. Rio de Janeiro. Civilização Brasileira, 1966. A segunda tradução ao português brasileiro, realizada por Bernardina da Silva Pinheiro,foi lançada apenas em 2005 pela editora Objetiva. Uma terceira tradução, de Caetano Galindo, foi publicada pela editora Companhia das Letras em 2012.
} 
Dessas traduções "clássicas", ou mesmo de traduções que foram as primeiras numa dada língua, origina-se uma tradição tradutória; isto é, construções textuais, frases, títulos e até mesmo jogos de palavras passam a ser considerados "unânimes" e "imutáveis", mesmo que tais traduções não funcionem tão bem para os membros de uma comunidade linguística que estejam temporalmente distantes das datas de suas produções. Essas características textuais de traduções alçadas a condição de tradicionais passam a influenciar o trabalho do tradutor e, em alguns casos, até mesmo restringem suas possibilidades de escolha. Isso não significa que o tradutor esteja fadado à cópia de um texto mais antigo; pelo contrário, aponta para o fato de que algumas soluções alcançaram uma originalidade na língua alvo que devem ser mantidas, e negá-las, introduzindo outras soluções, não necessariamente melhores, abalaria a constituição hereditária não apenas daquele texto, mas também da consciência cultural que se desenvolveu a partir dele.

Essa "originalidade" do tradutor pode ser avaliada de dois modos. Em primeiro lugar, sob a ótica do exagero linguístico; em segundo, do enriquecimento literário. Em alguns casos, o tradutor, querendo demonstrar sua capacidade artística e versatilidade linguística, exagera ao produzir seu texto, e introduz, sem necessidade, neologismos e estrangeirismos, ou altera morfologicamente palavras antigas para que pareçam criações completamente originais e com a sua assinatura; em alguns casos também eleva o nível linguístico e literário do texto, tornando-o mais difícil. Em contrapartida, o tradutor que cumpre sua tarefa sem a preocupação de se sobressair tem a possibilidade de enriquecer tanto linguística quanto literariamente a sua língua. Para Levý,

o tradutor pode e deve fazer valer completamente suas capacidades de criatividade linguística, quando tiver de transladar valores estilísticos que ainda não foram encontrados no desenvolvimento de sua literatura nacional. Preencher essas lacunas é justamente uma das tarefas do traduzir. (1969, p.83)

O tradutor contribui para o avanço de sua literatura quando consegue passar à poética de sua literatura nacional estilos e tipos literários que não existem, ou que ainda não tenham se desenvolvido tanto quanto na cultura fonte. Isso ocorre através da tentativa de recriação das estruturas gramaticais, sintáticas, estéticas, e outras, do texto fonte, e não apenas criando um texto na língua alvo que demonstre seu virtuosismo linguístico.

A teoria de Levý prevê e trabalha com dois modos de tradução: a tradução fiel e a tradução livre. Um deles preconiza a fidelidade e se atém a questões particulares do texto fonte; seu foco está no intercâmbio de material linguístico em detrimento da compreensão geral. O segundo modo busca preservar a forma e o conteúdo geral, não se preocupando em conservar as particularidades do texto fonte, mas substituindo-as por particularidades da cultura fonte. A partir disso, o teórico tcheco desenvolve três métodos fundamentais de trabalho do tradutor, regulados pela relação entre o particular e o geral; são eles:

- A substituição: quando não é possível preservar um elemento artístico particular que seja portador de um significado geral, mas se consegue comunicá-lo; por exemplo, quando um determinado personagem produz erros que interferem no sentido geral do texto, tais erros precisam ser substituídos na tradução. 
○ A transcrição: quando é possível preservar, mas não comunicar um recurso artístico que não possui significado geral; quando um nome não carrega nenhum sentido, por exemplo, Levý é categórico ao dizer que somente a transcrição é possível.

○ A tradução: quando é possível preservar e comunicar um recurso artístico.

Mais um ponto da problemática da tradução que compõe a teoria vista aqui está relacionado ao colorido nacional e histórico, já aludido vez e outra. Uma preocupação fundamental para o tradutor é escolher que papel as particularidades históricas e nacionais da cultura fonte exercerão no texto da tradução. As dificuldades quanto a isso já se iniciam na determinação de quais são propriamente essas particularidades, e se são mesmo pertencentes a uma dada cultura ou se fazem parte de uma consciência cultural internacional. É importante que o tradutor observe se a língua exerce um papel fundamental na constituição dessa particularidade, que perceba se os elementos linguísticos possuem significados específicos à cultura de que fazem parte, de forma que se possa mantê-los no texto traduzido na tentativa de preservar o colorido estrangeiro.

Entendendo a obra como um sistema que se constitui de outros subsistemas, a percepção por parte do leitor das diferenças culturais também é influenciada pela proporção entre o todo e as partes. As escolhas que o tradutor faz devem estar, dentro da teoria de Levý, voltadas ao todo em detrimento das partes. Ou seja, é mais recomendável optar por traduzir o todo estilístico do que focar-se nas partes isoladas que o compõem, visto que nem sempre se chegará ao mesmo resultado.

Um outro ponto importante da teoria de Levý é que tem uma abordagem funcional. De um ponto de vista prático, para ele, o principal foco do tradutor deve estar em compreender as funções constituídas no texto fonte e trazê-la ao texto alvo. Isso significa, por exemplo, que, quando os elementos linguísticos de uma frase possuem mais do que meramente um significado denotativo, apresentando também determinada função informativa ${ }^{19}$, a tarefa do tradutor é reproduzir primeiramente essa função, e somente depois, se for preciso, traduzir o significado denotativo das palavras, uma vez que a função pode estar fundamentada "em alguns dos menores elementos informativos (palavras), e normalmente é irrelevante quais desses devem ser preservados" (1969, p. 105). Assim, por exemplo, ao se deparar com um trocadilho, não é fundamental que o tradutor utilize as mesmas palavras em sua tradução; o que se pede é que consiga reconhecer o que está em jogo, e, assim, trazer tal trocadilho para a cultura alvo, exercendo a tradução função similar ao que se tem no original.

Quanto ao estilo da tradução, essa não se relaciona necessariamente com o estilo do texto fonte na medida em que aquele, em alguns casos, manifesta-se de modo mais normativo do que o do original; ou seja, onde o texto fonte traz uma expressão colorida e expressiva, "excedendo-se" em relação a um texto que segue as normas estilísticas vigentes, a tradução não segue obrigatoriamente o mesmo caminho, sendo considerada, portanto, estilisticamente adequada, porém inferior. Para que alcance o nível estilístico

${ }^{19}$ Funções informativas são elementos textuais semanticamente carregados que informa ao leitor o contexto da obra, o estilo do autor, o caráter de um personagem, o enfoque ideológico, etc. (Levý, 1969, p.105) 
elevado do original, o tradutor também precisa tentar ultrapassar os limites de sua língua, produzindo uma obra que esteja não apenas alinhada com modelos textuais, mas que também se compare ao de obras literárias de seu idioma.

O empobrecimento lexical originado na escolha de palavras está diretamente ligado à tentativa de produção de um texto estilisticamente normativo, sem deixá-lo manifestar-se como obra única e pura novidade. Isso ocorre de três formas: 1) quando o tradutor, com o intuito de facilitar o entendimento do texto, prefere utilizar palavras mais simples e gerais - que possuem um entendimento maior entre os leitores -, em vez de palavras específicas e com significados particulares; 2) quando abre mão de recursos expressivos, normalmente relacionados ao estilo do autor, utilizando palavras comuns e com valor estilístico neutro, tornando a obra "incolor"; e 3) por outro lado, escolhendo palavras que não apenas ressaltam o estilo, mas que intensificam os efeitos mais fortes e salientes do texto. Relacionado a isso, um cuidado que o tradutor deve ter é a medida de utilização dos sinônimos; isto é, o tradutor deve procurar valer-se dos sinônimos oferecidos por seu idioma e não se limitar a algumas poucas escolhas lexicais; em concomitância, deve ser capaz de perceber se uma palavra foi utilizada mais de uma vez de forma intencional no texto fonte, apresentando uma função definida, e, assim, procurar trazê-la ao texto alvo.

A interpretação é outro dos fatores que pode interferir na produção da tradução. Embora para realizar sua tarefa caiba a este interpretar a obra, muitas vezes o tradutor acaba transportando estruturas textuais veladas - parte do estilo da obra - ao primeiro plano. Ao fazer isso, quebra tensões entre o pensamento e a ação pretendidas pelo autor, e revela ao leitor da tradução aquilo que o leitor do texto fonte apenas desconfiava.

Quanto à tradução dos títulos, dois tipos principais são objeto da reflexão de Levý. Primeiro, os títulos chamados descritivos, comuns na Idade Média, mas que também ocorrem nas literaturas moderna e contemporânea. Esses títulos costumam trazer tanto o estilo da narrativa, o tema que será tratado na obra, quanto o nome do herói. Na relação entre as informações contidas no título e uma transformação estética do mesmo, o tradutor costuma preservar o caráter informativo, sendo que, em alguns casos, o tradutor mantém apenas a denominação temática, encurtando os títulos mais longos. Em segundo lugar, o teórico trata dos títulos simbólicos, mais variados, com um efeito mais particular sobre o leitor, e com maior inserção na cultura fonte. A dificuldade para o tradutor, por conta disso, aumenta; assim, em muitos casos, opta por utilizar uma forma nacional específica, como é o caso, por exemplo, da publicação de uma seleção de textos de determinado autor. Em português utiliza-se o termo Antologia, em inglês Selected (poemas ou contos, etc.), em alemão Ausgewählte... (textos, obras, etc.), em francês Oeuvres choisies. As dificuldades também se apresentam quando um título faz referência a uma situação social ou remete a um local específico da cultura fonte. Outrossim, é preciso que o tradutor observe quando um título já faz parte do arcabouço literário da cultura alvo, e se será útil tentar modificar esse elemento da tradição tradutória sem confundir o leitor e sem prejuízo para sua tradução.

Outro tópico abarcado pela reflexão teórica de Levý é a tradução teatral. A "falabilidade" do texto teatral traduzido se dá por meio das escolhas do tradutor. Quanto mais semelhante à linguagem coloquial estiver o texto traduzido melhor será compreendido pelo público. Essa inteligibilidade está associada 
à compreensão que o ouvinte tem do texto ao ouvi-lo pela primeira vez e será menor se as expressões utilizadas forem menos familiares, de modo que as falas dos personagens precisam ser pensadas para o público que irá recebê-las. Segundo Levý,

o ouvinte contemporâneo não está mais acostumado com os períodos desenvolvidos de modo complexo do diálogo teatral, razão pela qual os tradutores modernos frequentemente simplificam a sintaxe de dramas antigos. (1969, p. 129)

Além disso, o tradutor deve pensar de que forma se constitui a linguagem de palco em sua cultura, que pode variar em relação à linguagem coloquial. Cabe ao tradutor passar ao ator o modo como aquele estilo deve ser representado para o espectador, se a linguagem deve afastar-se do coloquial para aparentar uma falsidade, ou aproximar-se para transportar o público à realidade da peça. Além disso, a partir da fala do personagem, a interpretação do espectador, e do personagem para o qual a fala é dirigida, pode variar.

Os atos que constituem a natureza dramática do texto são passados ao público através de gestos, movimentos, e, sobretudo, de palavras. A escrita sugere, sem dizer explicitamente, em muitos casos, como o ator deve executar aquela fala. Assim, o tradutor deve ter uma percepção dos recursos estilísticos e do modo como o autor construiu seu texto, de forma que seja capaz de fazer chegar ao ator a mesma intensidade do conflito existente no texto fonte.

A construção dos personagens por meio dos diálogos é outro cuidado que o tradutor deve ter. Em alguns textos, a caracterização dos personagens se dá exclusivamente pela maneira como falam, e torna evidente seus papéis naquela representação. Alguns personagens, entretanto, são criados de forma dúbia e apresentados com duas faces, duas formas de discurso. Também existem aqueles que se caracterizam por um desenvolvimento gradual de suas características particulares - por exemplo, o antagonista não se apresenta como tal imediatamente, mas seu caráter vai "desabrochando" no decorrer da peça. Nesses casos, o tradutor deve tomar cuidado para não antecipar nenhum acontecimento ou mudança de caráter dos personagens. Uma das caracterizações mais difíceis, e onde se pode perceber o trabalho do tradutor como bem sucedido, é a dos personagens criados a partir de marcas linguísticas condicionadas social e nacionalmente, cujo efeito está ligado diretamente à experiência histórica e cultural do autor. Conseguir transladar essas características de uma forma que possam ser compreendidas pelos espectadores torna o trabalho do tradutor altamente elogiável.

Como se vê, a peça como um todo gera inúmeras dificuldades para o tradutor. Por conta disso, Levý propõe que o modo de trabalho de um tradutor de teatro não deve ser estático ou linear, mas deveria constituir um sistema de métodos variáveis com características elásticas, tendo por base a interpretação do tradutor; ou seja, em algumas partes o que importa é a manutenção do significado, em outras, o estilo deve sobrepor-se, ou a entonação, ou a preservação de peculiaridades históricas ${ }^{20}$. Pode-se dizer que "a interpretação do detalhe linguístico pelo tradutor é importante para o trabalho do ator sobre o papel, ou seja,

${ }^{20}$ LEVÝ, 1969, p. 153. 
para a orientação objetiva de toda a encenação" (Levý, 1969, p.158). Por meio de sua interpretação é que o tradutor reconhece as partes mais significativas do texto, da peça, e faz escolhas para trazê-las ao público.

Levý conclui a formulação de sua teoria com uma análise dos quesitos fundamentais para o historiador e o crítico literário estudarem este gênero de texto, a tradução. Assim, em uma análise histórica da tradução, o conhecimento do processo genealógico da obra configura-se como um elemento determinante para a constatação da relação entre a tradução e o texto fonte. Isso quer dizer que o historiador literário necessita descobrir qual texto serviu ao tradutor como fonte para o seu trabalho - como, por exemplo, se somente o original, ou o original e outras traduções em seu idioma, ou ainda traduções em outros idiomas. É fundamental reconhecer qual texto - ou textos - serviu ao tradutor como original e quais fontes ele utilizou como apoio para solucionar problemas e dúvidas. A partir do momento em que essa gênese tradutória for determinada, o historiador conseguirá chegar mais próximo do objetivo de seu estudo, a saber, desvendar os principais métodos que constituíram o trabalho do tradutor. Tal análise é realizada através de observações não de semelhanças, mas de diferenças entre a tradução e o texto fonte. São essas que revelarão ao crítico quais os caminhos percorridos pelo tradutor e onde seu estilo pessoal pode ter sobrepujado o da obra.

A análise aprofundada da tradução, iniciando em sua gênese e observando todas as escolhas do tradutor, pode esclarecer a relação entre os métodos de escrita tanto do texto fonte quanto do texto alvo, mas vai além: pode esclarecer que papel a tradução ocupou no desenvolvimento da literatura nacional, qual sua influência para outras obras literárias da cultura alvo, em outras palavras, que tarefa a tradução cumpriu na literatura e como a escolha da obra e dos recursos tradutórios foi condicionada por essa tarefa.

Com o avanço dos Estudos da Tradução, é possível perceber quão inovador foi o pensamento de Levý, e como sua figura de pesquisador e teórico da tradução eleva-se cada vez mais em relação aos seus contemporâneos. Mary Snell-Hornby, em The Turns of Translation Studies (2006), coloca Levý em uma posição de destaque não apenas como teórico da tradução, mas como um verdadeiro pioneiro da disciplina:

Levý cumpriu muito mais do que o papel de precursor, mas provou ser um dos pioneiros dos Estudos da Tradução modernos. Dentre as matérias de que tratou inclui-se a tradução de drama - por tanto tempo considerada uma enteada da disciplina -, com todos os problemas relacionados à falabilidade e à performabilidade, que viriam a ser discutidos nos anos 90 , e um terço do livro é dedicado à tradução do verso. (Snell-Hornby 2006, p. 22)

Levý acreditava que a tradução faz parte, enquanto gênero, de uma intrincada rede de significados no sistema de que faz parte uma obra literária. Cada palavra, efeito estético, ou mesmo referência social ou cultural, estão interligados entre si dentro do texto, mas também se conectam com outros textos dentro da tradição literária da qual provém. Assim, não via a tradução em seu caráter dicotômico de forma e sentido, mas ao buscar uma apreensão do valor estético da obra em sua totalidade pretendia que esse também fosse reconstruído no texto alvo. Além disso, pode-se dizer que ele superou a visão da tradução como ancilar e colocou-a em um novo patamar: a de um novo gênero literário. 
Finalmente, mesmo que sua intenção tenha sido dedicar-se exclusivamente à teorização da tradução literária, Levý produziu o que poderia ser considerada uma teoria geral da tradução, que apresenta instruções metodológicas com o intuito de auxiliar tanto a prática quanto a análise de traduções, o que pode ser considerado um dos impulsos iniciais para a formação dos Estudos da Tradução.

Filipe Mendes Neckel

filipe_neckel@hotmail.com

\section{Referências bibliográficas}

BROECK, Raymond van den. "Translational Interpretation: A Complex Strategic Game". In Translators' Strategies and Creativity: Selected Papers from the 9th International Conference on Translation and Interpreting, Prague, September 1995: In Honor of Jiř Levy and Anton Popovic. Prague: International Conference on Translation and Interpreting, 1995. Kralova, J.; Mercer, B. M.; Ozeroff, A. B. Amsterdam: John Benjamins B.V., 1998.

JetTMArovÁ, Zuzana. "Czech and Slovak Translation Theories: The lesserknown Tradition". In: Tradition versus Modernity: From the classic period of the Prague school to translation studies at the beginning of the $21^{\text {st }}$ century. KRÁlovÁ, J.; JeTTMAROVÁ, Z.; et al. Praga: 2008.

. Translating Jiř́ Levý's Art of Translation for an International Readership. In: Posibilidades y límites de la comunicación intercutural. Jana KRÁlovÁ (org.). Praga: Karolinum Press, 2011.

. Traduzindo The Art of Translation de Jiří Levý para um Público Internacional. Trad. de Gustavo Althoff e Gustavo Sartin. In: Scientia Traductionis, $\mathrm{n}^{\mathrm{o}}$ 11, p. 132-152, jul. 2012.

LEVÝ, Jiř́i. Die literarische Übersetzung. Theorie einer Kunstgattung. [Trad. Walter Schamschula] Frankfurt a.M.: Athenäum Verlag, 1969.

A tradução literária. Teoria de um gênero literário (Excerto). As três fases do trabalho tradutório. Trad. de Filipe M. Neckel e Marcelo Rondinelli. In Scientia Traductionis, n ${ }^{\circ}$ 11, p. 24-60, jul. 2012.

. Translation as a decision Process. In The Translation Studies Reader. Lawrence VenUti (Org.). New York: Routledge, 2000.

. A Tradução como um Processo de Tomada de Decisão. Trad. de Gustavo Althoff e Crsitiane Vidal. In: Scientia Traductionis, $\mathrm{n}^{\mathrm{o}}$ 11, p. 7296, jul. 2012.

SnEll-HornBy, Mary. The Turns of Translation Studies: New paradigms or shifting viewpoints?. Amsterdam: John Benjamins B.V., 2006.

Vega CernudA, Miguel Ángel. "El caso Levý: Fenomenología de su recepción y valoración de sus aportaciones en el contexto de la Traductología de la época". In Posibilidades y límites de la comunicación intercutural. Jana KRÁlovÁ (org.). Praga: Karolinum Press, 2011.

. O caso Levý: Fenomenologia de sua recepção e avaliação de suas contribuições no contexto da Tradutologia da época. Trad. de Mauri Furlan. In: Scientia Traductionis, nº 11, p. 153-171, jul. 2012. 